\title{
SOCIAL CAREER INFLUENCES OF XHOSA ADOLESCENTS ELICITED USING THE SYSTEMS THEORY FRAMEWORK IN A PERI-URBAN SOUTH AFRICAN TOWNSHIP
}

\author{
A. J. Albien* \\ e-mail: anouka@sun.ac.za
}

\section{A. V. Naidoo*}

e-mail: avnaidoo@sun.ac.za

*Department of Psychology

Stellenbosch University

Stellenbosch, South Africa

\section{ABSTRACT}

The present study describes social-level influences on black high school learners from a periurban township of career choices that were elicited using the qualitative career measure, My System of Career Influences ( $\mathrm{MSCl})$. The prominent influences on the career decision-making processes of isiXhosa-speaking adolescents included family, school and peer relationships, as well as media role models and cultural factors. While family support was salient, limited direct parental involvement in career planning was voiced. The school context provided rich examples of influences, such as subject mastery, that helped build self-efficacy beliefs and vicarious learning. In contrast, friends were described as both supportive and negative influences. Africentric narratives of overcoming hardship and adversity were explored that seemed to form resilient mechanisms strongly linked to a black racial identity. The reconciliation of 'western' career aspirations with rural cultural expectations in forming a coherent self-concept may be the greatest challenge in vocational identity development for black adolescents.

Keywords: career development, career influences, black adolescents, Systems Theory Framework, My System of Career Influences.

\section{INTRODUCTION}

The South African society is divided in terms of inequality, with a minority of the population living in a first-world context in comparison to a third-world context inhabited by the majority of the population (Watson 2010, 24). This suggests that the individual career development of the majority of black South Africans cannot be contextualised effectively if the apartheid legacy of social inequality and oppression is not recognised as circumscribing vocational decisions (Naidoo, Pretorius and Nicholas in press, 4). The apartheid system imposed social and 
economic legislations to entrench the political and social privilege of a hegemonic white minority (Theron, Cameron, Didkowsky, Lau, Liebenberg and Ungar 2011, 802). The apartheid government designated specific occupational privileges to certain races, with black people relegated to the lowest skilled and lowest paid occupations (Naidoo et al. in press, 6).

Post-apartheid socio-political changes attempted to address the historical divisions and inequalities through policy developments, which have increased expenditure on education and removed occupational restrictions for black adolescents (Salisbury 2016, 43). However, the task of choosing a career remains formally unaided for many learners (Akhurst and Mkhize 2006). Traditional career options for black matriculants were limited to teaching, nursing, social work and office work professions, reflecting the interplay between cultural norms and apartheid job restrictions (Maesala 1994; Watson, McMahon, Foxcroft and Els 2010). In the current research, the voices of adolescents who are struggling to emerge from the shadow of the apartheid legacy are presented, with a focus on the social-level influences that shape their navigation through a newly opened labyrinth of career opportunities.

The influence that parents, peers as well as other social factors have on adolescents' career decisions goes largely unrecognised in trait-and-factor approaches (i.e. Holland 1997; Watson and Stead 2006a, 18). Furthermore, Super’s developmental stages (Super, Savickas and Super 1996) may not adequately reflect the career development paths and context of disadvantaged black youth, who rarely have opportunities to explore and try out jobs of their choice. This has resulted in lower career maturity scores being documented in several studies (De Bruin and Bernard-Phera 2002; Van Niekerk and Van Daalen 1991; Watson and Van Aarde 1986; Watson, Stead and De Jager 1995). The construct of role salience has also been called into question with the acknowledgement that the meaning of work is deciphered through different cultural lenses (Ferrari, Nota, Soresi, Blustein, Murphy and Kenns 2009, 99-100).

Additionally, Social Cognitive Career Theory (SCCT) has attempted to place the individual in-context as a product and producer of his/her environment (Alexander, Seabi and Bischof 2010, 497; Bandura 1986). Specifically, on a social level, vicarious learning and social persuasion have been indicated to influence an individual's career self-efficacy beliefs (Lent, Brown and Hackett 2002, 36). Although considerable gains have been made in both theory and practice, cultural diversity has remained an elusive concept that is divorced from real-life career counselling situations, particularly in developing countries like South Africa (Maree 2010a, 354; Maree 2012, 1). However, gaining insight into social and cultural career influences could help create culturally sensitive career counselling techniques that respect isiXhosa-speaking adolescents and their individual needs. 
The present study pursued a comprehensive exploration of the personal framing and negotiation of social-level career influences using the Systems Theory Framework (STF) as an overarching framework. The STF can provide a means of engaging with clients from traditionally marginalised groups and can offer a mechanism to explore the impact of overlooked career influences (e.g., culture, rural locations and disadvantaged socio-economic conditions) (Arthur and McMahon 2005, 213). Although the individual is central to the STF, the strength of the STF is that it can be customised to accommodate clients whose career development occurs within collectivistic cultures (McMahon 2005, 35). A qualitative assessment based on the STF, the My System of Career Influences (MSCI; McMahon, Patton and Watson 2005a), was used to explore the social influences that affect Xhosa adolescents' career decision-making.

In the present research, social-level career influences are defined according to the STF as the people systems with which individuals interact. Social influences pertain to the interpersonal resources, such as family and community contexts, which are posited to facilitate career decision-making or provide barriers. These social career influences include family, educational institutions, peer and community groups as well as the media, which all form subsystems of the social system (Patton and McMahon 2006, 154). Here the term 'influence' is a neutral term that affords participants the opportunity to assign positive or negative connotations to career influences (McMahon 2005, 36). The assigned connotations were used to explore how each of the social levels of career influences contain enablers and barriers, as well as the interrelationships between these influences that can provide the individual with an opportunity to narrate his or her own career development.

The underlying assumption of social constructivist theory is that individuals live according to specific narratives that they have constructed about themselves or that significant others have constructed about them or for them (McIlveen and Patton 2006, 23; McMahon, Patton and Watson 2003, 198). In these narratives, meaning is constructed actively through social interaction and relationships within a specific context (Maree 2010b, 363). Therefore, storytelling can be used to reflect the diversity of the human experience and to help identify the influences of significant others in career development processes to determine how subjective career realities are created (McMahon and Patton 2002, 30; Savickas 2002, 383). Stories represent a mechanism by which individuals can 'construct their identities from the symbols or meanings on offer within their culture' (McLeod 1996, 178). A multicultural focus becomes a necessity within a South African context, where diverse languages and cultures co-exist and to which Eurocentric career counselling approaches and practices previously were applied to 
unanimously (Maree, Ebersöhn and Molepo 2006). This article aims to provide a description of the 'multistoried' socio-cultural influences that affect the career behaviour present in a case study of black adolescents living in a peri-urban township. The telling of career stories can enable an active search for meaning in the participants' post-apartheid career development, as well as provide insight into the culturally sensitive career counselling needs present in this sample.

Previous research has described the necessity of ascertaining how culture and language constitute the individual's symbolic world, which affects meaning-making processes such as career decisions (Savickas 1993). There is a dearth of South African post-apartheid research that describes socio-cultural influences in career behaviour and includes the rich diversity of African indigenous collectivistic knowledge systems. The dominant use of western values and beliefs in South African career research that centre around rational and independent career decision-making as well as a nuclear family structure has ignored collectivistic elements in African cultures (Watson and Stead 2002, 26). In traditional African cultures there is a focus on being part of a group aligned with the belief of Ubuntu (the spirit of togetherness or personhood through others) (Kamwangamalu 1999). In collectivistic cultures, such as the isiXhosa-speaking sample in this research, group career counselling and storytelling can aid adolescents in narrating and pursuing ideas of a culturally-centred meaningful life (Watson and Stead 2002, 30).

The qualitative story-telling approach, specifically applying the MSCI, was found to be effective in research conducted on rural and urban middle-class Australian secondary school learners (McIlveen, Morgan and Bimrose 2012, 22). In a South African context, the MSCI has been used successfully with low socio-economic urban black secondary school learners, as well as with middle-class urban white and black secondary school learners (Dullabh 2004; Kuit 2006). The usefulness of the MSCI across a diverse group of individuals has been demonstrated previously (McMahon and Watson 2012).

As a meta-theoretical account of career development, the STF depicts a comprehensive range of two categories of constructs. Content and process influences contextualise important intrapersonal variables relevant to career behaviour (McIlveen, McGregor-Bayne, Alock and Hjertum 2003, 6; McMahon, Watson, Foxcroft and Dullabh 2008, 533; Patton and McMahon 2006, 153; Watson and McMahon 2006, 161). As a construct category, content influences refer to the individual influence system (e.g., age, personality, gender, beliefs, interests and ethnicity), the social influence system (e.g., family, school, peers and the media) and the environmentalsocietal influence system (i.e., geographic, political and socio-economic factors) (Arthur and 
McMahon 2005, 212; McIlveen et al. 2003, 195). Therefore, the individual is perceived as a system and part of a greater contextual system consisting of the social and environmentalsocietal systems (Patton and McMahon 2006, 155). Process influences include the multidirectional interaction between various sub-systems of influences, which includes past, present and future development (McMahon and Watson 2008, 56). However, for the purposes of this study, only the social-level influences were to determine significant social webs of meaning and how these have shaped career decisions.

\section{METHOD}

\section{Research design}

A qualitative case study research design (Stake in Denzin and Lincoln 2000) according to social constructivist theory underpinnings was utilised in this study to present rich descriptions of the participants’ experiences (Maree 2010b, 363; Maree and Beck 2004, 83). In this manner, a complex and layered understanding of black adolescents' constructions of their pertinent sociallevel systems of career influences provide a contextualised understanding of career development trajectories amongst township youth. A qualitative instrument (MSCI) was used to engage the participants in individual and group interviews to examine both the negative and positive influences of social contexts and embedded relationships on their career development processes.

\section{Participants}

Purposive sampling was used to select participants, with the main selection criterion being that participants had to be Grade 12 learners from the Kayamandi township. Kayamandi means 'Sweet Home' in isiXhosa and is an informal settlement of approximately 40000 residents on the northern outskirts of the Stellenbosch Cape Winelands district, about $50 \mathrm{~km}$ from Cape Town. Kayamandi began as a compound for black workers and was incorporated into the Stellenbosch Municipality as a suburb in 1994 (Rock 2011, 94). Kayamandi residents appear to be employed predominantly in the service sector in lower paying jobs (e.g., domestic work, gardening, transport and other manual labour) (Darkwa 2006, 72). High levels of poverty in the community are accompanied by attendant social conditions such as crime, substance abuse and malnutrition. There are two high schools in Kayamandi. However, due to logistical constraints the sample was drawn from only one of the two high schools. At this particular high school, the Grade 12 learners were the first group of matriculants at the school. While all Grade 12 learners 
(47 in total) were invited to participate, the final sample consisted of 12 learners, comprising three girls and nine boys. The participants in the sample were between 17 and 20 years old $(\mathrm{M}=18.4, \mathrm{SD}=0.65)$.

The demographic information of the participants is presented in Table 1 and includes gender, home language and parents' education levels and occupations. IsiXhosa was the home language of 83 per cent of the participants. Parents' education levels and occupations were separated by gender to compare the education levels achieved by the mothers and fathers, as well as their respective occupations. Fathers with a low level of education constituted the highest percentage (50\%), whereas 33 per cent of the mothers had a low level of education. Interestingly, more mothers had achieved Grade 11 and 12 levels of education (50\%). This can be contrasted with only one father in the sample who had a Grade 12 level of education (8.3\%). Although mothers had higher education levels, the occupations reported were low-paying and semi-skilled jobs.

The participants' career ideas are presented in Table 2. Career ideas included accounting, business, marketing, management, auditing, economics, tourism, human resource management and entrepreneurship. However, some other career ideas were mentioned, such as radio/TV presenter, sportsman, flight attendant, tour guide/operator, travel agent, mathematician and social worker. Three learners did not indicate any career ideas, which may be an indication of career uncertainty. All the career ideas mentioned were highly paid and seemed to be genderneutral occupations.

Table 1: Demographic data of the Grade 12 sample

\begin{tabular}{|l|l|c|c|}
\hline \multirow{2}{*}{ Measures } & & Sample group (n= 12) & \% \\
\hline Gender & Male & F & 75.0 \\
& Female & 3 & 25.0 \\
\hline Home language & IsiXhosa & 9 & 75.0 \\
& IsiXhosa \& English & 2 & 16.7 \\
& Not given & 1 & 8.3 \\
\hline Mother's education & Less than Grade 4 & 3 & 25.0 \\
& Grade 4 & 1 & 8.3 \\
& Grade 9 & 1 & 8.3 \\
& Grade 10 & 1 & 8.3 \\
& Grade 11 & 2 & 16.7 \\
& Grade 12 & 4 & 33.3 \\
\hline Mother's job & Cook & 1 & 8.3 \\
& Housewife & 1 & 8.3 \\
& Domestic worker & 2 & 16.7 \\
& Self-employed & 1 & 8.3 \\
& Unemployed & 6 & 50.0 \\
& Not answered & 1 & 8.3 \\
\hline Father's education & Less than Grade 4 & 6 & 8.0 \\
& Grade 4 & 1 & 8.3 \\
& Grade 8 & 1 & 16.7 \\
\hline
\end{tabular}




\begin{tabular}{|l|l|c|c|}
\hline \multirow{2}{*}{ Measures } & & Sample group $(\boldsymbol{n}=\mathbf{1 2})$ & F \\
\hline & Grade 10 & 1 & 8.3 \\
& Grade 12 & 1 & 8.3 \\
\hline Father's job & Factory worker & 2 & 16.7 \\
& Petrol attendant & 1 & 8.3 \\
& Truck driver & 1 & 8.3 \\
& Mine worker & 2 & 16.7 \\
& Taxi driver & 1 & 8.3 \\
& Water proofer & 1 & 8.3 \\
& Unemployed & 3 & 25.0 \\
& Not answered & 1 & 8.3 \\
\hline
\end{tabular}

Table 2: Career ideas taken from the demographic questionnaire

\begin{tabular}{|l|c|}
\hline Career ideas listed (3 for each learner) & Sample group $(\boldsymbol{n}=\mathbf{1 2})$ \\
\hline Actuarial science & 1 \\
Auditor & 2 \\
B Commerce (marketing) & 3 \\
Businesswoman & 1 \\
Chartered accountant & 2 \\
Economist & 1 \\
Entrepreneurs & 1 \\
Human resources & 1 \\
Mathematician & 1 \\
Radio/TV presenter & 2 \\
Social worker & 1 \\
\hline Sports & 2 \\
Management & 1 \\
Professional & 1 \\
\hline Tourism & 8 \\
Guide & 1 \\
Operator & 1 \\
Travel agent & 2 \\
Flight attendant & 1 \\
Management & 2 \\
Marketing & 1 \\
\hline Learners who did not answer & 3 \\
\hline
\end{tabular}

\section{MEASURE}

A qualitative career assessment instrument derived from the STF of career development, the My System of Career Influences (MSCI; McMahon et al. 2005a), was used to collect data. The MSCI was developed over a timespan of four years and was subjected to a three-stage crossnational trialling process (McMahon et al. 2003; 2004; 2005b). The MSCI (McMahon et al. 2005b, 11) is adaptable for either individual or group career-counselling processes and has been found to be effective in assisting socio-economically disadvantaged learners, who found the experience valuable and enjoyable, as reported by Dullabh (2004). The MSCI is a twelve-page booklet divided into five sections that enable guided reflection on current career situations, with instructions, examples and space to respond in the booklet.

In Section 1 of the MSCI workbook, My present career situation, seven open-ended questions are presented related to: current career decisions, work experience, life roles, 
occupational aspirations, decision-making approaches and people who have provided advice. Each of the interrelated systems of influence in the STF is represented diagrammatically in Section 2. The three most important influences in each step need to be indicated with an asterisk. The first step, Thinking about who I am, is based on the intrapersonal system of influences, with reflection on influences such as interests, personality, gender, health and culture. The second step, Thinking about the people around me, is based on the social system of influences, with reflection on family, friends and media. The third step, Thinking about society and environment, is based on the environmental-societal system of influences, with reflection on financial support, local area and public transport. The fourth step, Thinking about my past, present and future, contextualises time, using reflections on past role models and future lifestyle aspirations. The fifth step, Representing my system of career influences, integrates the information gained in the preceding steps and results in a personalised diagram of the individual's system of career influences. Section 3 of the MSCI workbook, Reflecting on my systems of career influences, is a reflection process guided by 11 open-ended questions. However, Section 4, My action plan, and Section 5, My system of career influences 2, were not included in the study. This research was limited to eliciting the adolescents' social-level systems of career influences using the second step, Thinking about the people around me of section 2, as well as the 11 open-ended questions in Section 3 as a semi-structured interview schedule for individual interviews and a focus group interview. The MSCI was not available in isiXhosa at the time of this study; however, as adequate English proficiency levels were established, an isiXhosa translator was not needed.

\section{PROCEDURE}

Ethical approval was granted by Stellenbosch University's ethics review committee and from the Western Cape Department of Education (WCED) prior to data collection. Written permission was obtained from the principal of the school for the Grade 12 learners to be interviewed. The researcher's prior involvement at the school facilitated credibility and access to the learners. Both parental consent and learner assent were obtained, as it was assumed that learners would predominantly be under 18 years of age in Grade 12. This assumption reflects more middle-class, urbanised school environments, in comparison to the school in question in Kayamandi. Principals, educators and learners were under no obligation to assist with this research, and special care was taken not to interrupt education programmes. Permission to record the interviews electronically was requested. The anonymity and confidentiality of the data were assured with data coded to protect participant identities. Interview data were stored 
electronically for data analysis and were accessible only to the researcher, the research supervisor and an external researcher for transcription. The participants were provided with contact details of resources to provide further career counselling support.

Data collection constituted a four-phase research process, from May to September 2011. The lengthy structure of the research process was based on recommendations in the MSCI facilitator's guide, which included examples of systemic and systematic thinking (McMahon et al. 2005b, 12-13; 2008, 534). A facilitative role was played by the researcher in guiding the group of participants through the various levels of influences in completing the MSCI. Firstly, an introduction to the research was provided, which entailed the completion of a narrative exercise and demographic questionnaire. Secondly, the MSCI booklet was completed in a group setting over three sessions. Thirdly, individual participants were invited to discuss their experiences of completing the MSCI booklet, guided by 11 open-ended questions in an interview schedule. Reflective interviews took 30 to 40 minutes to complete and were conducted in an empty classroom on the school premises after school to avoid interference with the academic syllabus. The last research phase was the focus group interview. Due to ethical stipulations, a short career development session was held with the Grade 12 learners of the school, as well with as the Grade 12 learners at the other high school in Kayamandi who did not participate in this research. This ensured that these learners also had exposure to a career development intervention providing unique opportunities for reflection and career development, which might otherwise not have been received.

\section{DATA ANALYSIS}

Thematic content analysis based on the STF framework was used to extract themes from the individual interviews. A focus group interview was used to confirm the prominent influences identified at the social, societal-environmental and process levels that could be addressed in career development (McMahon et al. 2004, 15; Patton, McMahon and Watson 2006, 74). However, the current findings focus specifically on the thematic content analysis of the social level of career influences using specific codes to describe the data. The presentation of qualitative themes as well as the description of the adolescents' subjective career stories may help to facilitate the exploration of new and critical issues in career counselling for marginalised South African youth (Ebersöhn and Mbetse 2003, 323; Stead, Els and Fouad 2004, 218).

\section{FINDINGS AND DISCUSSION}

The verbal accounts, which are represented below, allowed individuals to identify their own 
unique constellation of social-level influences. These included parents, teachers, peers, mentors, the media and cultural influences. By creating an opportunity for participants to narrate their own career development stories, references to racial and social prejudices, poverty and injustices can be transcended (Alexander, Seabi and Bischoff 2010; Maree 2010b, 363). Learning about the interaction of various social elements, both positive and negative, that constitute the systems of career influences helped to develop an understanding of what was important and why (McMahon and Watson 2009, 191). In this way, using the MSCI to facilitate the content and process of career development (McMahon et al. 2008, 537), prominent social influences of career development and vocational identity were made visible to the Grade 12 learners, who were facing the end of their high school education. See Appendix A for Table 3 that provides a summary of the themes identified in the data.

\section{Social-level influences}

Social-level influences form an important aspect of career choice that previously was overlooked. Individuals subjectively define themselves through their social contexts (Patton and McMahon 2006, 156). Specifically, in adolescence, influences in the social context play a more visible role for young people than those in the environmental-societal system, due to the importance attached to peer and social interactions in adolescence (McMahon 2005, 31). The social career influences elicited in the data include extended family support, school, friends, community mentors, the media and cultural influences as subsystems of the social system (Arthur and McMahon 2005, 212).

Previous research has documented the importance attached to occupational information and guidance from parents, teachers and peers (Shumba and Naong 2012). In addition, socioeconomic disadvantage was found to be outweighed by the combined micro-variables of extended family support, parental availability and positive role models (Dass-Brailsford 2005, 584). Although the identification of these influences is important, the priority afforded, as well as the subjective meanings, are located within a cultural context that needs recognition (McMahon and Watson 2009, 191).

Social constructionism views people who share meaning making in their relationships as being part of one or more cultures, which can be inclusive or separate from race, ethnicity and language (Stead 2004, 393). Culture refers to collective conventions, values and practices indigenous to specific groups (Van der Walt and Bowman in Theron et al. 2011, 801). Cultural diversity in the present research is specified according to group membership, based on cultural variables such as ethnicity, race, gender, sexual orientation, ability and age (Arthur and 
McMahon 2005, 209). Although these collective practices define, maintain and interconnect group members, some hegemonic cultural practices may limit and oppress individuals (Van der Walt and Bowman in Theron et al. 2011, 801). Individuals have multiple simultaneous memberships of different social collectives and thus have multiple identities with varying degrees of salience. In a South African context, the most salient social identity groups are selfclassifications of race, gender, ethnicity and language (Booysen 2007). However, a deeper understanding of cultural dynamics and nuances in career development is needed.

Cultural backgrounds, which form part of social career influences, can create different career aspirations, values, attitudes, enablers and barriers to career decision-making processes (Msila 2015, v). There is a scarcity of cultural research on career development in a South African context that interprets career development from an Africentric perspective amongst isiXhosa-speaking township youth (Theron, Theron and Malindi 2013, 65). Therefore, the decision was made to draw on existing resilience research in order to begin building a culturally informed career research knowledge base. Culture was found to promote resilience through extended families, religious structures and ethnic social systems that encourage adaptive behaviour (Masten and Powell in Theron et al. 2011).

\section{Family support}

Parents' positive attitudes to education were seen to be a significant positive influence on this group and resulted in a great value being placed on tertiary learning. Supportive parents was identified as a subtheme and was observed in the following excerpts: 'My parents support me every day' (Participant (P.) 1), 'I mean like my family is backing like supporting me' (P. 8.) and 'You can say my parents they just motivate me in what I want' (P. 3). Parents were identified as a motivational and supportive career influence, which is supported by previous research (Seabi, Alexander and Maite 2010). However, the parents of this sample were seen to be unable to provide tacit assistance with career choices in an ever-changing technological environment, as many parents had low-level, unskilled or semi-skilled positions and were not qualified to assist (or felt unqualified to provide advice). The Reticence of parental involvement in career planning was identified as a subtheme, and was identified as a negative influence or barrier by the respondents. This can be seen in the following excerpt when the MSCI booklet was discussed with participant 6 , who said in relation to his parents: 'they just have no idea what I'm talking about. So I just find useless to tell them or ask them.' Similarly, respondents P. 12 and P. 9 explained that 'None of them is educated so they don't know much about those careers' and 'they don't know what IT is'. 
Career information was seen to be an assemblage of factual and stereotypical snippets collected from various sources, such as parents, friends, teachers and TV, resulting in statements such as this one: 'I don't want to be like Sam in Generations because he was travelling overseas and then he became a bartender. [My mother] was confused that maybe I'll end up in that situation' (P. 2). Adolescents presented the limited career information they had gathered to their parents, who often had different ideas of what a worthwhile career was. These career ideas were partial remnants of apartheid job restrictions and often had a limiting effect on the career information that was taken into consideration by their children. The positive and negative influence that parents have on career development can be seen in the following excerpt: 'So when you go and find that those things and you tell them, they become supportive to you although they don't know that much. Cause most of our parents in our culture they know things like teaching, nursing and being a mayor' (P. 7).

All 12 participants viewed their parents as moral influences that were symbolic and inspirational (Swartz 2011, 109). Parents were cited as significant positive influences or role models on the basis of their work ethic and sacrifices made for their families. Participant 12, whose mother was the breadwinner, working as a dishwasher in a restaurant, described his family situation as follows: 'For me I have to get finance. Because my brother, the one he's in CPUT [a local university]. My elder brother, he’s doing his second year now. He’s got bursary also. And my sister got a bursary from Stellenbosch. So, my mother cannot like help us. Cannot be able to support us ....'

Career development was characterised by insufficient career planning support, as well as limited financial resources within a family context, which presents barriers to career decisionmaking processes (Akhurst and Mkhize 2006, 149-150; Seabi, Alexander and Maite 2010, 494). Limited financial means often negatively influenced adolescents to consider entering the job market to help earn an additional income for their family, to the detriment of pursuing further education (Munsaka 2009, 71).

As a part of the extended family support structure, Supportive older siblings formed the second subtheme identified by four participants (33.3\%). Siblings provided assistance particularly in the absence of a father or if participants had moved from the Eastern Cape. Six participants had migrated from the Eastern Cape, the majority without their parents. Siblings helped with application forms and encouraged career choices, as some were studying to become professionals such as accountants (P. 2). Participant 12 mentioned: 'I only first knew about it when my brother was talking about actuarial science'. In addition, siblings attempted to create opportunities for each other. According to participant 10, his move to the Western Cape was 
based on what his sister had told him: 'Let's open opportunities for you and come to us and so I came here to study. They believe that there are many opportunities here and there are many varsities, so I can be brought education and they can take care of me as my parents did.' Participant 4 claimed that his older sister was as supportive as she could be, even though she had other priorities: 'Because she is also busy with her own marriage'. If siblings were living in campus residences or were too busy, participants often did not consider asking them and turned to the school environment as another channel of available information.

\section{School environment}

There was strong dependence on the local schools as a resource for planning and constructing the participants' future (Mampane and Bouwer 2011, 124). The influential role that this educational environment plays in adolescent career development has been documented by significant increases in career maturity by grade (Watson and Van Aarde 1986, 14). In reality, many township schools have overcrowded classes, broken equipment, a lack of computer facilities and limited teacher-to-learner interaction. Notwithstanding this, the participants perceived their school as an important community asset that provided a multitude of resources.

The first subtheme extracted was Life Orientation (LO) teachers. All 12 participants described LO teachers as valuable and helpful sources of information and support. Although these teachers faced numerous time constraints, they attempted to instil resilience and inspiration in their learners to overcome the adversity in their development (Mampane and Bouwer 2011, 115). Participant 7 recounted that he went to his teacher and told her about 'a vision that I will become an economist', and she informed him about what this career path entailed. Moreover, participant 2 explained the significant influence that her LO teacher had on her career choice: 'It's my miss, she encourage me. I like tourism and she like tourism and teach it.' Furthermore, one of the LO teachers had organised a job-shadowing experience for five learners at PricewaterhouseCoopers. The LO class time was stipulated as the only space where careers were discussed, within time and syllabus constraints, and prescribed assignments also played an important role in career development processes, as pointed out by participant 9: 'There's a project that we were given that we have to find ... career things so I found that [IT] is a career that I want'.

The school environment was perceived as an important platform where resources, support and examples of mastery were provided. As a second subtheme, School subjects was endorsed by seven participants (58.3\%). Subjects provided instances to discern abilities through observational learning as well as social persuasion from teachers' feedback. Participant 12 
explained that 'they have seen my marks in maths. And they believe that if it's maths all the way then I will definitely do it.' This arena for observing personal abilities and the rewards of hard work was seen to have an influence on self-confidence and self-esteem. Participant 3 repeated what he had heard from his teachers regarding his abilities: 'Like my teacher said I'm good at talking to people. I think my vocabulary is better. At school I think I'm good at business and business studies.' In contrast, school marks also represented barriers to further education, and low performance in English prohibited university entrance: 'Other people tell me in other place like university or college they don't need the person who get code two [40\%] in English. So I don't know what I'm going to do' (P. 1).

\section{Friends}

The first subtheme extracted in relation to friends was Friends acting as support structures, which was cited by 10 participants (83.3\%). The exchange of ideas, resources, support and information among friends resulted in pro-social behaviours (Shefer 2011, 94). The narrative below indicates the role that participant 9's friends played in helping him improve his maths marks: 'If we are talking about different careers if someone has a problem, ja we can help each other out. I was struggling with maths but they helped me a lot.' Participant 5 realised the important support structures in which she was embedded: 'I've learned that there are people that are closer to me they're also my supporters. Such as my parents and also friends.' Similarly, participant 8 described his experience of the social web of friendship: 'How to choose the friends that help you stick ... that will help you to reach your goal. That will not say to you, you cannot reach it. You cannot make it. That will support your every time and that will give you the good impression every time like, support you about your career.'

In contrast, peers were also construed by the participants as negative influences or barriers. The negative effects of peer pressure included substance abuse, violence, unwanted pregnancy, risky sexual behaviour, gang membership and lack of academic motivation (Shefer 2011, 94). All 12 participants acknowledged the potential negative influence that friends could have. The MSCI presented a unique opportunity to analyse the negative comments encountered. A second subtheme, of friends as negative influences that needed to be ignored, emerged. In the sample, five participants mentioned they needed to 'Ignore them [friends]' (P. 4) and realised 'not to listen to my friends. Learn to work as a group in order to fulfil the dream. Because when you find something [you] find enemies sometimes' (P. 1). Participant 9 described his positive selftalk in countering negative comments: 'I found because people are actually telling me that oh it's so difficult you won't make it. I told myself that if I will listen to those people I won't make 
it for real.' Negative influences consisted mainly of the communication of discouraging messages, specifically that it was not possible for participants to succeed: 'You can't do it' (P. 7).

The participants' consideration that they could be different from anyone else in the Kayamandi community was discouraged, as participant 1 recounted: 'They said I'm wasting my time because maybe at the end of the year I will fail.' Participant 6 described how he aimed to use his self-efficacy beliefs as a shield from the critical comments that he had encountered: 'I know what to accept from other people although, not to take the negative things but to take them as an opportunity for me to succeed.' Participant 12 explained how negative comments about the difficulty of the course affected him and made him doubt himself: 'I said I'll go for it because I love maths and I know my abilities of maths. I'll definitely do that course. But, at the same time, people are making me to become scared of the course ... I can see the reaction of the people when I'm mentioning this course [actuarial science] and most of them they say that we were also good at maths at school. This is totally different from the math that we know.'

Negative influences have the potential to compromise self-efficacy beliefs and expectations. In addition, peer pressure has the potential to pull these participants in contradictory moral directions. Friends also were the source of illegal activities and instigated others to get involved in substance abuse or money-making schemes. For example, participant 4 described his experience of resisting this pervading pressure: 'I know I can commit fraud. Ja. But I don't want to. Most of my friends asking me why man let's do this and this you know I say I'm not comfortable my friend you know. Do your own thing I'll do my own thing you know.'

The range of negative influences described above adds to the already existing challenging circumstances in Kayamandi. Negative comments may compromise self-efficacy beliefs in the absence of community role models who endured the same conditions to create stories of career success.

\section{Role models}

None of the participants in the sample was aware of anyone from their community who attended university or further occupational training courses (viz., no visible role models). This formed the first subtheme of a lack of role models in the Kayamandi community. This lack of vicarious learning examples was seen to reinforce doubt about whether they could 'make it' (Chung 2002, 282; Smith, Chambers and Bratinin 2009, 161). Many training opportunities were located towards Cape Town. Consequently, students who could be potential mentors lived in student 
residences and were not visible in the community. Participant 12 confirmed that 'I've just collected information from the library and the internet. I haven't met anyone who's doing actuarial science.' However, participant 12 and participant 11 had been selected to attend a South African Institute of Chartered Accountants (SAICA) camp as the top two learners of the school. Participant 12 explained how his confidence and self-efficacy beliefs were reinforced when he met other learners who 'were like me. We're all in the same level ... we've done a test there of maths and none of them get below 80 per cent. We started from 80 per cent upwards and there was a lot of 100 per cent into that class.'

The second subtheme extracted was Chance encounters, which created informal mentoring relationships in which career information was shared and vicarious learning occurred. Chance brought eight participants of the sample into contact with another person seen as a mentor, someone who was a valuable source of career information, insight and friendship. Participant 6 had a chance encounter with a UWC student who was trying to help him to complete his application. Participant 12 had met a student who had been helping him with applications since Grade 10, although specific information about actuarial science was lacking. Participant 5 met a student in Khayelitsha who was in her third year of tourism management at CPUT and was helping her search for bursaries. Similarly, participant 7 met a friend from Zimbabwe and said: 'He helped me a lot through communication and attending libraries.' Participant 3 had met a family friend who 'was doing business management at UNISA. He's the reason that I chose this subject that I'm doing right now.' Lastly, participant 8 explained: 'So I meet a sister and she was accountant. She gave me the bursary and it was my first time grabbing the bursary.'

However, often all the essential questions about course details or critical discussion about career options were not engaged with in these mentor relationships. In addition, restricted funds and access may prevent rural and peri-urban adolescents from building positive support networks that serve to strengthen their resilience (Markstrom, Marshall and Tryon in Kerperlman and Mosher 2004, 188). Family and community members observed educational and occupational obstacles in the examples of university graduates who had returned to the community unemployed. In the absence of accessible community role models, media role models are frequently used as substitutes. Career information and role models were also sourced from media sources such as television (TV), radio and newspaper (Watson and McMahon 2006, 162). Eight participants highlighted the importance of local TV programmes as significant career influences. This formed the third subtheme of Media role models, based on soap operas such as Generations, Muvhango and Ekasi: Our stories. These TV series provide glimpses of 
occupational realities that are novel and unknown in the Kayamandi community. However, career stereotypes were created and career decisions were influenced by romanticised career ideals. Participant 10 described his change in career choice based on the commercialised image of businessmen earning a lucrative salary, as portrayed on TV: 'The business people; ja they were like they were getting a lot of money but ja the feeling changed, the dream changed. I wanted to do commercial subjects.' The outside world was presented mainly through media sources due to a perceived disjuncture between living in the township and venturing into the business area of Stellenbosch. Although the Kayamandi township is a peri-urban settlement, the surrounding farmlands result in a pejorative rural image associated with the township, which seemed to isolate the adolescents socially and culturally.

\section{CULTURAL INFLUENCES}

Career development is influenced by different cultural values, which affect perceptions of career choices and behaviours (Maree 2010b, 71). Identity and culture are both seen as fluid, with changes in and reintegration of social identity occurring. This implies that, through different contexts, individuals will change their attitudes to the self and others, which simultaneously will alter the social group with which they identify (Booysen 2007, 4). The current research follows the stance proposed by Stead $(2004,39)$ that it may be more appropriate to determine the influence of culture on career choices, rather than only attempting to determine or describe the nature of the respondents' culture. Traditionally, African culture implies that an Africentric way of being is embedded or 'anthropocentric' (Bujo 2009, 115), where individuals integrally form part of a larger community (Theron, Theron and Malindi 2013, 66).

One important cultural value is that of Ubuntu. Although the interpretation of the term differs, the underlying values do not. The philosophy of Ubuntu teaches reverence for human interdependence (Mkhize in Theron et al. 2013, 66). The meaning of Ubuntu was cited by participant 9: 'in working with people. I believe that a person is a person because of other people.' The participants initially had difficulties in articulating cultural elements that informed worldviews and desirable careers. Further probing solicited detailed descriptions that included dignity, honesty, integrity, hard work, wanting respect and being respected, as well as being influenced by and influencing other people. Participant 8 described cultural values that revolved around pooling resources by community members: 'To go to the people, give back to the community, don't be selfish like wasting things, I'm talking about money now, like share with your family and others'. 
One way to understand culture is to view it as giving members of that particular cultural group access to in-group resources, which include sharing narratives, information, education, access to community members and common values (Stead 2004, 394). Values are believed to arise from people's needs and are important motivators of behaviour (Maree 2010b, 73). Most significantly, the first subtheme of Narratives of overcoming hardship emerged, with all 12 respondents referring to this subtheme. Hardship was linked to the struggle that was waged by the participants' parents. Participants wanted to utilise the possibilities gained through the struggle against apartheid. For example, participant 9 explained that: 'Being a Xhosa person I think from the struggle that our parents have gone through that's what I'm telling myself they have made us free. Our parents suffered for many years and now there are only few that are earning under that suffering, under those tears and blood. That built South Africa.' According to Theron (2013, 534), these narratives of suffering shared amongst family and community members perform protective functions and result in resilience. It has been hypothesised that resilience processes are based on the protective layer formed by extended family. Narratives of overcoming past suffering are told to encourage perseverance and individual mastery, as the individual's educational success is conceptualised to benefit the whole family (Theron and Theron, 2012). Learned helplessness could be mitigated by a cultural reframing of setbacks, hence not interpreting them as personal failure but rather as meaningful events (Utsey, Bolden, Lanier and Williams 2007, 89). The protective mechanisms that underpinned resilience in this sample were based on individual agency, constructive meaning making of hardship faced and supportive extended family networks (Theron and Theron 2013, 402).

Culture simultaneously may create boundaries and limits to safeguard elements of cultural and group identity. Fitzgerald and Betz (in Stead 2004, 394) commented on the constraining role that cultural factors play in career choice, of which gender socialisation is an example. Gender differences in career decision-making processes were anticipated and Cultural conceptualisations of gender was extracted as the second subtheme. In the patriarchal African culture, the male is expected to be the breadwinner. In reality, households and families are fragmented, with grandmothers or single mothers often supporting their families (Ramphele 2002). Yet the interviews revealed that being a male was an important influence, mentioned by five respondents. Disparities between genders did not manifest in occupations contemplated (see Table 2). However, the male respondents felt it was an inherent part of their role as a man to be the main financial provider and decision maker of a family unit. The significance attached to male identity was explained by participant 8: 'Since like in our culture when you are a male. It's like the head of the home. So, when I'm at the job my word will be valuable at the job. It's 
not like I'm saying that the female voice is not heard. But, since I am a man - and you can see on the Generations ... when he’s talking everybody listens. So it’s since I am a male, my opinion will be considered in the decision-making.'

Male participants reported more future-orientated behaviours, with career developmental tasks and deadlines. In contrast, the three female respondents had only thought of immediate career concerns, such as training opportunities for the next year. In addition, they had considered a limited range of career options and lacked assertiveness to ask teachers for advice: 'Ha aha me I'm, I'm too shy to ask teachers' (P. 5). None of the female respondents was going to participate in a work-shadowing experience. The male respondents' assertiveness had resulted in the LO teachers organising work-shadowing opportunities for them. The career behaviour observed in the male respondents supports previous studies, where black male youths were found to have more positive career-related self-efficacy expectations and to have considered a greater number of high-paying careers (Seane in De Bruin and Bernard-Phera 2002, 1). In contrast, female counterparts indicated limited career ideas and less self-efficacy expectations. This can be conceptualised as a gender barrier to career choices that needs to be explored further in future research studies.

Although Africentricism may provide a protective mechanism, it can also frustrate ambitions (Theron 2013). Therefore, the participants' stories may differ from or contradict the stories told by others in the individual's system of influences, for example stories told by the family and friends. Although no story is free from contradiction or ambiguity, there ultimately is a need for acculturation. Culture is by no means static and acculturation refers to the extent to which individuals have absorbed new traditions, discarded old ones, or have adapted to accommodate other ways (Stead 2004, 396). Integration refers to a positive attitude towards both the own culture and the host culture, whereas assimilation is an acceptance of the new culture but a negative attitude towards one's own culture (Stead 2004, 397). In contrast, separation is a positive attitude towards one's own culture but a negative one towards the host culture. Marginalisation is a negative view towards one's own culture as well as the host culture (Berry and Sam, 1997).

The incorporation of western elements of career planning into the Xhosa culture was met with opposition and suspicion by some participants, which can be likened to the separation acculturation method. When attending training institutes and facilities near the city of Cape Town, individuals were thought to be exposed to western values, which challenged cultural values. Although Ubuntu is still widely honoured, the adoption of egocentric or competitive values (individualistic cultures) may threaten cohesiveness and cause confrontation between a 
rapidly westernising society and a more traditional society (Bujo in Theron et al. 2011, 802803; Stead 1996, 272). The third subtheme, Resistance to western values, was evident in the responses of all 12 participants. Although cultural attitudes and beliefs are deeply engrained, apartheid served to accentuate the differences between communities and cultures at the expense of their similarities. The tension between Xhosa cultural values and western values can be seen in the following excerpt: 'Not forget where you come from and who you are. That's the big thing. When I'm an accountant, like saying ok, now I have my money. So I can leave the Xhosa people. I want to be there in the Eastern Cape with them. Not saying that ok, I'm educated, I have my money, I'm rich now I'm going to be overseas or here and there. I want to be there [in the Eastern Cape]' (P. 8).

Cultural narratives of hardship shared by family members meant that the participants believed that their disadvantaged background gave them the strength to succeed. These narratives also created cautiousness regarding negative cultural labels and perceived jealousy associated with materialistic success and 'westernness'. The movement to areas where training and career opportunities exist could reduce the reinforced boundaries between cultural groups and decrease resistance to being 'western'. An Africentric narrative of becoming 'too western' was seen to limit the opportunities considered. However, research on transitioning from high school to tertiary education shows that young people can be perceived as being different, leaving old friends behind and facing the problems arising from the experience of living between two worlds (home and campus) (McIlveen at el., 2012). The adolescents' career choices and options observed in the sample supported recent findings that show how rural adolescents are affected by geographic location, stereotyping, family loyalty and cultural obligations (Durey, McNamara and Larson in McIlveen et al. 2012, 23). The potential impact of cultural influences and acculturation processes needs to be explored further, and includes the influence of the environment on the participants, such as the effect of urbanisation on sociocultural factors like language usage (Maree, Ebersöhn and Molepo 2006).

\section{CONTEXTUAL CONSIDERATIONS AND LIMITATIONS OF THE STUDY}

The MSCI as a reflective career development exercise could enable adolescents to overcome their disadvantage by ensuring that they are aware of the need for continuous re-formulation of their career decisions, plans and goals (McIlveen, Everton and Clarker 2005, 71). Nevertheless, the effects that discrimination, ethnic identity and unemployment have on career development processes in this sample are undeniable (Nicholas, Naidoo and Pretorius 2006, 2; Watson and Stead 2006b, 61). The STF is particularly useful for recognising the historical and political 
influences of past apartheid practices that have led to a post-apartheid focus on selfdetermination, thereby incorporating cultural diversity (Arthur and McMahon 2005, 219). The findings of the current research, while very informative, were obtained from a limited purposive sample and cannot be generalised to the Kayamandi population, or to disadvantaged adolescents in other townships. However, the findings of this study open possibilities for further research studies to examine the social influences affecting the career ideas of black adolescents, who have to integrate family and cultural considerations into their career aspirations. The career narratives elicited by completing the MSCI enabled individuals to gain insight into their career development and career choices (McIlveen 2007, 5-8).

The limitation of using an English-based measure with non-mother tongue English participants is central to the contextual findings of this study. While being helpful in facilitating a dialogue on career influences, the language and unfamiliar diagrammatic nature of the MSCI may present challenges that may frustrate rather than facilitate the career exploration process. There is a great need for career assessment measures to be translated into the indigenous languages of South Africa. An isiXhosa version of the MSCI is currently being developed. However, creating a simplified version of the MSCI for second-language English speakers is also recommended. In order to facilitate the reflection needed to complete out the MSCI, a precursory cognitive processing opportunity is recommended to incorporate diverse information and create familiarity with mind-mapping exercises. Further considerations should also be given to utilising the MSCI to promote experiential and reflective learning as a group career exploration process, with exercises that allow the processing of inputs from individuals in the group.

\section{CONCLUSION}

The present research has demonstrated the complexity inherent in adolescent career decisionmaking processes, especially in low-income environments that provide multiple examples of vocational barriers. Cultural identity emerged as a significant influence in an individual's career development. Adolescent learners need to be guided to explore how social and cultural influences may exert an influence on their career decision-making processes (Arthur and McMahon 2005, 215-216). While the MSCI has utility in facilitating an exploration of social and other influences on career development, translating this resource into isiXhosa or simplifying the structure may address some of the critiques raised by the participants.

The present findings shed light on the cultural terrain of Africentric narratives and systems of meaning making in a context of coping with poverty, inequality and hardship. In the post- 
apartheid context, cultural understandings are essential to enable a respectful exploration of career opportunities and planning in an adolescent group that faces formidable career adjustment difficulties (Stead 1996, 274). Because adolescents from low-income communities are such an under-researched group, research is needed to provide cogent accounts of their experiences and the social-level influences to which adolescents are subjected. Longitudinal and comparative research should be conducted on the use of the MSCI in other under-researched groups and diverse cultural groups in the South African context (Stead and Watson 2006, 181). The meaning making that disadvantaged adolescents undergo, based on their unique constellation of social career influences and the resultant storytelling, is intrinsic to understanding local South African career identities embedded in township communities and enabling protection against vulnerability (McMahon and Watson 2008, 287).

\section{REFERENCES}

Akhurst, J. and N. Mkhize. 2006. Career education in South Africa. In Career psychology in the South African context, ed. G. B. Stead and M. B. Watson, 139-151. 2nd ed. Pretoria: Van Schaik Publishers.

Alexander, D., J. Seabi, and D. Bischoff. 2010. Efficacy of a post-modern group career assessment intervention of disadvantaged high school learners. Journal of Psychology in Africa 20(3): 497500.

Arthur, N. and M. McMahon. 2005. Multicultural career counselling: Theoretical applications of the systems theory framework. The Career Development Quarterly 53: 208-222.

Bandura, A. 1986. Social foundations, thought and behaviour: Social cognitive theory. EnglewoodCliffs, NJ: Prentice-Hall.

Berry, J. W. and D. Sam. 1997. Acculturation and adaptation. In Handbook of cross-cultural psychology, ed. J. W. Berry, M. H. Segall and C. Kagitçibasi, 291-326. 2nd ed. Boston, MA: Allyn and Bacon.

Booysen, L. 2007. Societal power shifts and changing social identities in South Africa: Workplace implications. South African Journal of Economic and Management Sciences 1: 1-20.

Bujo, B. 2009. Is there a specific African ethic? Towards a discussion with Western thought. In African ethics: An anthology of comparative and applied ethics, ed. M. F. Murove, 113-128. Scottsville: University of KwaZulu-Natal Press.

Chung, Y. B. 2002. Career decision-making self-efficacy and career commitment: Gender and ethnic differences among college students. Journal of Career Development 28(4): 277-284.

Darkwa, I. 2006. Post-occupancy evaluation of state-subsidised housing units in Kayamandi, Stellenbosch. Master's thesis. Stellenbosch University, Stellenbosch, South Africa.

Dass-Brailsford, P. 2005. Exploring resiliency: Academic achievement among disadvantaged black youth in South Africa. South African Journal of Psychology 35(3): 574-591.

De Bruin, G. P. and M. Bernard-Phera. 2002. Confirmatory factor analysis of the Career Development Questionnaire and the Career Decision-making Self-efficacy Scale for South African high school students. South African Journal of Industrial Psychology 28(2): 1-6.

Denzin, N. K. and Y. S. Lincoln, eds. 2000. Handbook of qualitative research. Thousand Oaks, CA: Sage.

Dullabh, A. 2004. The career development of adolescents in a children's home: A career systems perspective. Master's thesis, Nelson Mandela Metropolitan University, Port Elizabeth, South 
Africa.

Ebersöhn, L. and D. J. Mbetse. 2003. Exploring community strategies to career education in terms of the asset-based approach: Expanding existing career theory and models of intervention. South African Journal of Education 23(4): 323-327.

Ferrari, L., L. Nota, S. Soresi, D. L. Blustein, K. A. Murphy and A. C. Kenna, 2009. Constructions of work among adolescents in transition. Journal of Career Assessment 17(1): 99-115.

Holland, J. L. 1997. Making vocational choices: A theory of vocational personalities and work environments. 3rd ed. Florida, FL: Psychological Assessment Resources.

Kamwangamalu, N. M. 1999. Ubuntu in South Africa: A sociolinguistic perspective to a Pan-African concept. Critical Arts 13(2): 24-41.

Kerperlman, J. L. and L. S. Mosher 2004. Rural African American adolescents' future orientation: The importance of self-efficacy, control and responsibility, and identity development. Identity: An International Journal of Theory and Research 4(2): 187-208.

Kuit, W. 2006. The career development of South African Grade 11 adolescents: A career systems and discursive perspective. Master's thesis, Nelson Mandela Metropolitan University, Port Elizabeth, South Africa.

Lent, R. W., S. D. Brown and G. Hackett. 2002. Social cognitive career theory. In Career choice and development, ed. D. Brown and Associates, 255-311. 4th ed. San Francisco: Jossey-Bass.

Maesala, J. P. 1994. A study of black matric pupils who make traditional career choices versus nontraditional career choices with regard to personality traits, vocational needs and family background. Master’s thesis, Stellenbosch University, Stellenbosch, South Africa.

Mampane, R. and C. Bouwer. 2011. The influence of township schools on the resilience of their learners. South African Journal of Education 31: 114-126.

Maree, J. G. 2010a. Editorial: Reassessing career counselling in Africa in the 21st century: Breathing new life into qualitative approaches. Journal of Psychology in Africa 20(3): 353-358.

Maree, J. G. 2012. Career counselling in the $21^{\text {st }}$ century: Merging qualitative and quantitative approaches to facilitate 'best practice'. Cypriot Journal of Educational Sciences 7(1): 1-6.

Maree, J. G. and G. Beck. 2004. Using various approaches in career counselling for traditionally disadvantaged (and other) learners: Some limitations of a new frontier. South African Journal of Education 24(1): 80-87.

Maree, K. 2010b. Career counselling: Methods that work. Cape Town: Juta and Company Ltd.

Maree, K., L. Ebersöhn, and M. Molepo. 2006. Administering narrative career counselling in a diverse setting: Trimming the sails to the wind. South African Journal of Education 26(1): 49-60.

Mcllveen, P. 2007. A test for theoretical integration: Systems theory framework and dialogical self. Australian Journal of Career Development 16(3): 31-37.

Mcllveen, P. and W. Patton. 2006. A critical reflection on career development. International Journal for Educational and Vocational Guidance 6: 15-27.

McIlveen, P., B. Everton and J. Clarker. 2005. A university career service and social justice. Australian Journal of Career Development 14(2): 63-72.

McIlveen, P., H. McGregor-Bayne, A. Alock and E. Hjertum. 2003. Evaluation of a semi-structured career assessment interview derived from systems theory framework. Australian Journal of Career Development 12(3): 1-24.

McIlveen, P., T. Morgan and J. Bimrose. 2012. A longitudinal study of the experience of a career development program for rural school students. Australian Journal of Career Development 21(1): 22-30.

McLeod. J. 1996. The emerging narrative approach to counselling and psychotherapy. British Journal of Guidance and Counselling 24: 173-184.

McMahon, M. 2005. Career counselling: Applying the systems theory framework of career 
development. Journal of Employment Counselling 42: 29-38.

McMahon, M. L. and M. B. Watson. 2008. Systematic influences on career development: Assisting clients to tell their career stories. The Career Development Quarterly 56: 280-288.

McMahon, M. and M. Watson. 2009. Career psychology research challenges: A systems theory response. South African Journal of Psychology 39(2): 184-194.

McMahon, M. and M. Watson. 2012. Systemic influences on adolescent career stories: Integrating theory, research and practice. IAEVG International Conference: Career Guidance for Social Justice, Prosperity and Sustainable Employment - Challenges for the $21^{\text {st }}$ Century. https://www.iaevg-conference-2012-mannheim.com/fileadmin/redaktion/abstracts/Schiersmann _Christiane_2_02.pdf (accessed 20 October 2012).

McMahon, M. and W. Patton. 2002. Using qualitative assessment in career counselling. International Journal for Educational and Vocational Guidance 2(1): 51-66.

McMahon, M., M. Watson, C. Foxcroft and A. Dullabh. 2008. South African adolescents' career development through the lens of the systems theory framework: An exploratory study. Journal of Psychology in Africa 18(4): 531-538.

McMahon, M. L., W. Patton and M. Watson. 2003. Developing qualitative career assessment processes. The Career Development Quarterly 51: 194-202.

McMahon, M. L., W. Patton and M. Watson. 2004. Creating career stories through reflection: An application of the systems theory framework of career development. Australian Journal of Career Development 13(3): 13-17.

McMahon, M., W. Patton and M. B. Watson. 2005a. My systems of career influences (MSCI): Adolescent workbook. Camberwell, Victoria, Australia: ACER Press.

McMahon, M. L., W. Patton and M. Watson. 2005b. My system of career influences (MSCI) facilitator's guide. Camberwell, Australia: ACER Press.

Msila, V. 2015. Ubuntu: Shaping the current workplace with (African) wisdom. Randburg: Knowres Publishing.

Munsaka, E. 2009. An investigation into the influence of family and community on school dropout among rural adolescents in Zambia. New Voices in Psychology 5(2): 64-77.

Naidoo, A. V., T. B. Pretorius and L. Nicholas. In press. The emergence of career psychology in South Africa: A socio-historical perspective. In Career psychology in the South African context, eds. G. B. Stead and M. B. Watson, 1-25. 3rd ed. Pretoria: Van Schaik Publishers.

Nicholas, L. J., A. V. Naidoo and T. B. Pretorius. 2006. Historical perspective of career psychology in South Africa. In Career psychology in the South African context, ed. G. B. Stead and M. B. Watson, 1-10. 2nd ed. Pretoria: Van Schaik Publishers.

Patton, W. and M. McMahon. 2006. The systems theory framework of career development and counseling: Connecting theory and practice. International Journal for the Advancement of Counselling 28(2): 153-166.

Patton, M., M. McMahon and M. Watson 2006. Career development and systems theory: Enhancing our understanding of career. In Career psychology in the South African context, ed. G. B. Stead and M. B. Watson, 65-78. 2nd ed. Pretoria: Van Schaik Publishers.

Ramphele, M. 2002. Steering by the stars. Being young in South Africa. Cape Town: Tafelberg.

Rock, D. 2011. The location shall be called Kaya Mandi: A history of Kaya Mandi. Master's thesis, Stellenbosch University, Stellenbosch, South Africa.

Salisbury, T. 2016. Education and inequality in South Africa: Returns to schooling in the post-apartheid era. International Journal of Educational Development 46: 43-52.

Savickas, M. L. 1993. Career counselling in the postmodern era. Journal of Cognitive Psychotherapy: An International Quarterly 7: 205-215.

Savickas, M. L. 2002. Reinvigorating the study of careers. Journal of Vocational Behaviour 61: 381- 
385.

Seabi, J., D. Alexander and O. Maite. 2010. Parental involvement in career development among disadvantaged adolescents. Journal of Psychology in Africa 20(3): 491-496.

Shefer, T. 2011. Adolescence. In Psychology: An introduction, ed. L. Swartz, C. de la Rey, N. Duncan, L. Townsend and V. O’Neil, 86-98. 3rd ed. Cape Town: Oxford University Press.

Shumba, A. and M. Naong. 2012. Factors influencing students' career choice and aspirations in South Africa. Journal of Social Sciences 33(2): 169-178.

Smith, L., D. Chambers and L. Bratini. 2009. When oppression is the pathogen: The participatory development of socially just mental health practice. American Journal of Orthopsychiatry 79(2): 159-168.

Stead, G. B. 1996. Career development of black South African adolescents: A developmental-contextual perspective. Journal of Counselling and Development 74: 270-75.

Stead, G. B. 2004. Culture and career psychology: A social constructionist perspective. Journal of Vocational Behaviour 64: 389-406.

Stead, G. B. and M. B. Watson. 2006. Indigenisation of career psychology in South Africa. In Career psychology in the South African context, ed. G. B. Stead and M. B. Watson, 181-190. 2nd ed. Pretoria: Van Schaik Publishers.

Stead, G. B., C. Els and N. A. Fouad. 2004. Perceived career barriers among South African high school learners. South African Journal of Psychology 34(2): 206-221.

Super, D. E., M. L. Savickas and C. M. Super. 1996. The life-span, life-space approach to career development. In Career choice and development: Applying contemporary theories to practice, ed. D. Brown, L. Brooks, and Associates, 121-178. 3rd ed. San Francisco, CA: Jossey-Bass.

Swartz, S. 2011. Ikasi: The moral ecology of South Africa's township youth. Johannesburg: Wits University Press.

Theron, L. C. 2013. Black students' recollections of pathways to resilience: Lessons for school psychologists. School Psychology International 34: 527-529.

Theron, L. and A. Theron. July 2012. Beating the odds of poverty: Stories from resilient South African students. Paper presented as the International Congress of Psychology, Cape Town.

Theron, L. C. and A. Theron. 2013. Positive adjustment to poverty: How family communities encourage resilience in traditional African contexts. Culture and Psychology 19(3): 391-413.

Theron, L. C., A. M. C. Theron and M. J. Malindi. 2013. Toward an African definition of resilience: A rural South African community's view of resilient Basotho youth. Journal of Black Psychology 39(1): 63-87.

Theron, L., C. A. Cameron, N. Didkowsky, C. Lau, L. Liebenberg and M. Ungar. 2011. A 'day in the lives’ of four resilient youths: Cultural roots of resilience. Youth and Society 43(3): 799-818.

Utsey, S. O., M. A. Bolden, Y. Lanier and O. Williams. 2007. Examining the role of culture-specific coping as a predictor of resilient outcomes in African Americans from high risk urban communities. Journal of Black Psychology 33(1): 75-93.

Van Niekerk, E. C. and H. J. Van Daalen. 1991. Career development of tertiary students: Some pertinent issues. Vital (Vista Teaching and Learning) 6: 7-13.

Watson, M. 2010. Career psychology in South Africa: Addressing and redressing social justice. Australian Journal of Career Development 19(1): 24-29.

Watson, M. B. and G. B. Stead. 2002. Career psychology in South Africa: Moral perspectives on present and future directions. South African Journal of Psychology 32(1): 26-31.

Watson, M. B. and G. B Stead. 2006a. An overview of career theory. In Career Psychology in the South African context, ed. G. B. Stead and M. B. Watson, 13-34. 2nd ed. Pretoria: Van Schaik Publishers.

Watson, M. B. and G. B Stead. 2006b. The career development of Donald Super. In Career psychology 
in the South African context, ed. G. B. Stead and M. B. Watson, 51-64. 2nd ed. Pretoria: Van Schaik Publishers.

Watson, M. B. and J. A. van Aarde. 1986. Attitudinal career maturity of South African coloured high school pupils. Journal of Vocational Behavior 29: 7-16.

Watson, M. and M. McMahon. 2006. My systems of career influences: Responding to challenges facing career education. International Journal of Educational and Vocational Guidance 6: 159-166.

Watson, M. B., G. B. Stead and A. C. de Jager. 1995. The career development of black and white South African university students. International Journal for the Advancement of Counselling 18: 39-47.

Watson, M., M. McMahon, C. Foxcroft and C. Els. 2010. Occupational aspirations of low socioeconomic Black South African children. Journal of Career Development 37(4): 717-734. 


\section{APPENDIX A:}

Table 3: A description of the social-level themes extracted from individual interviews

\begin{tabular}{|c|c|c|c|c|c|}
\hline Level & Themes & Sub-themes & $\mathbf{n}$ & $\%$ & Verbatim examples \\
\hline \multirow[t]{13}{*}{ Social } & \multirow[t]{3}{*}{$\begin{array}{l}\text { 1. Family } \\
\text { support }\end{array}$} & - Supportive parents & 12 & 100 & $\begin{array}{l}\text { 'My parents support me every } \\
\text { day'; 'I mean like my family is } \\
\text { backing like supporting me'; 'You } \\
\text { can say my parents they just } \\
\text { motivate me in what I want'. }\end{array}$ \\
\hline & & $\begin{array}{l}\text { - Parents' lack of } \\
\text { involvement }\end{array}$ & 12 & 100 & $\begin{array}{l}\text { 'None of them is educated'; 'They } \\
\text { don't know what IT is'. }\end{array}$ \\
\hline & & - Supportive siblings & 4 & 33.3 & $\begin{array}{l}\text { 'She's just supporting'; 'My brother } \\
\text { was talking about'. }\end{array}$ \\
\hline & \multirow[t]{2}{*}{$\begin{array}{l}\text { 2. School } \\
\text { environment }\end{array}$} & - LO teachers & 12 & 100 & $\begin{array}{l}\text { 'It's my miss'; 'Our teachers: Ms } \\
\text { Ndzamela and Mrs Gosani'. }\end{array}$ \\
\hline & & - School marks & 7 & 58.3 & $\begin{array}{l}\text { 'My marks in'; 'my teacher said I'm } \\
\text { good at'; 'At school I think } \\
\text { l'm good at'. }\end{array}$ \\
\hline & \multirow[t]{3}{*}{$\begin{array}{l}\text { 3. Role } \\
\text { models }\end{array}$} & - Lack of role models & 12 & 100 & $\begin{array}{l}\text { 'I haven't met anyone who's } \\
\text { doing'; 'Never met anyone with my } \\
\text { career'. }\end{array}$ \\
\hline & & - Chance encounters & 8 & 66.7 & $\begin{array}{l}\text { 'The people that I've met'; 'I've } \\
\text { met also'. }\end{array}$ \\
\hline & & - Media role models & 8 & 66.7 & $\begin{array}{l}\text { 'Generations'; 'Muvhango'; 'On } \\
\text { television'; 'TV'. }\end{array}$ \\
\hline & \multirow[t]{2}{*}{ 4. Friends } & - Support structure & 10 & 83.3 & $\begin{array}{l}\text { 'We can help each other'; 'My } \\
\text { supporter'; 'Friends that help you } \\
\text { stick'; 'Give me advice'. }\end{array}$ \\
\hline & & - Negative influence & 12 & 100 & $\begin{array}{l}\text { 'I don't want to listen to friends'; } \\
\text { 'Enemies'; 'I won't make it.' }\end{array}$ \\
\hline & \multirow[t]{3}{*}{$\begin{array}{l}\text { 5. Cultural } \\
\text { influences }\end{array}$} & $\begin{array}{l}\text { - } \\
\text { surratives of } \\
\text { suffering }\end{array}$ & 12 & 100 & $\begin{array}{l}\text { 'Those suffering'; 'Tears and } \\
\text { blood'; 'Struggle'; 'Our parents are } \\
\text { suffering'; 'It's all about people'. }\end{array}$ \\
\hline & & $\begin{array}{l}\text { - } \text { Cultural gender } \\
\text { conceptualisations }\end{array}$ & 5 & 41.6 & $\begin{array}{l}\text { 'Since I am a man'; 'Head of the } \\
\text { home'; 'He's talking everybody } \\
\text { listens'. }\end{array}$ \\
\hline & & $\begin{array}{ll}\text { - } & \text { Resistance to } \\
& \text { western values }\end{array}$ & 12 & 100 & $\begin{array}{l}\text { 'The Xhosa people'; 'Not forget } \\
\text { where you come from'. }\end{array}$ \\
\hline
\end{tabular}

